\title{
Proposta de uma Ferramenta Tecnológica Focada no Auxílio na Educação de Jovens e Adultos
}

\author{
Anderson M. de Morais ${ }^{1}$, Katyeudo Karlos de S. Oliveira1, Jaíne de S. Santos², \\ Robson S. de Oliveira ${ }^{2}$
}

${ }^{1}$ Programa de Pós-Graduação em Informática Aplicada (PPGIA)

Universidade Federal Rural de Pernambuco (UFRPE)

Rua Dom Manoel de Medeiros, s/n, Dois Irmãos, CEP 52171-900, Recife - PE - Brasil

${ }^{2}$ Universidade Federal do Agreste de Pernambuco (UFAPE)

Av. Bom Pastor, s/n, Boa Vista, CEP 55292-270, - Garanhuns - PE - Brasil.

\{anderson.ufrpe, karlos.1914.so,jayne_siqueira,robssantoss\}@gmail.com

\begin{abstract}
This work presents the proposal to develop the Connected EJA tool, created for use in the classroom as an aid to the pedagogical practices of the teacher, contributing to the process of literacy in Youth and Adult Education. The tool is based on Paulo Freire's literacy method, which considers students with their life experiences and forms of knowledge of the literate world. The different types of content are presented, organized in modules, with interactive activities that allow the student to practice reading, comprehension and text production skills, as well as the design resources used in programming.
\end{abstract}

Resumo. Este trabalho apresenta a proposta de desenvolvimento da ferramenta EJA Conectada, criada para uso em sala de aula como auxílio as práticas pedagógicas do professor, contribuindo, no processo de alfabetização na Educação de Jovens e Adultos (EJA). A ferramenta é baseada no método de alfabetização de Paulo Freire que considera os alunos com suas experiências de vida e formas de conhecimento do mundo letrado. São apresentados os diversos tipos de conteúdo, organizados em módulos, com atividades interativas que permitem ao aluno praticar as habilidades de leitura, compreensão e produção de textos, assim como os recursos de design utilizados na programação.

\section{Introdução}

A alfabetização é entendida como um processo particular e imprescindível de apropriação da escrita, o êxito dos conceitos alfabéticos e ortográficos que proporcionam ao indivíduo ler e escrever de forma autônoma [Val 2006]. Na perspectiva dos métodos sintáticos, alfabéticos, silábicos e fonéticos, o ato de ler trata-se de traduzir em sons as letras, frases e textos [Leal, Albuquerque e Morais 2010]. Porém, existe uma parte da sociedade que não teve acesso ao processo de alfabetização durante seus anos iniciais de vida, por diversos fatores sociais [Braga e Mazzeu 2017].

Segundo dados do Instituto Brasileiro de Geografia e Estatística - IBGE, a taxa de analfabetismo das pessoas de 15 anos ou mais no Brasil vem caindo, chegando a 6,8\% em 2018 [IBGE 2018]. Uma das ações que visa diminuir o analfabetismo é o programa de Educação de Jovens e Adultos (EJA), que visa contemplar o ensino para 
pessoas que estão fora da faixa de idade para frequentar as salas de aulas do Ensino Fundamental ou Médio. No entanto, é necessário haver uma metodologia de ensino diferente da que é aplicada em crianças de séries iniciais, tendo como base a não infantilização da alfabetização, visto que o grupo que frequenta o programa já tem uma visão muito mais ampla do mundo em que vive. Para este público, é mais relevante a percepção que eles têm acerca do próprio progresso, a motivação e o interesse em prosseguir no aprendizado [Ortiz et al. 2019].

Atualmente, é possível notar uma ampla disseminação da tecnologia em todos âmbitos da sociedade, novas ferramentas e o avanço das mídias digitais revolucionaram a maneira como as pessoas se comunicam, estudam, trabalham e se divertem numa perspectiva de cibercultura e convergência digital [Lévy 1999], [Santaella 2008], [Jenkings 2009]. Partindo disso, é possível facilitar o processo de alfabetização através do uso de recursos tecnológicos em sala de aula, visto que, é permitido constatar que tais recursos possuem potencial e caráter adaptativo para alunos e professores, possuindo flexibilidade e receptividade para ferramentas tecnológicas no cotidiano escolar [Oliveira et al. 2019], [Silva et al. 2019].

Existem diversas ferramentas digitais que não só auxiliam na alfabetização, mas em diversas outras áreas do conhecimento. No entanto, a maior parte delas, são destinadas ao público infantil, poucas são voltados para a EJA. Assim, este trabalho propõe a construção de uma aplicação web, seguindo o método de alfabetização proposto por Paulo Freire (1979), buscando promover a alfabetização considerando a realidade em que o indivíduo está inserido. A ferramenta visa especificamente os alunos da modalidade de ensino EJA, com o intuito de facilitar o seu aprendizado e servir como suporte ao trabalho do professor em sala de aula. Denominamos o sistema de EJA CONECTADA. O trabalho é organizado em: Seção 2 traz a metodologia; Seção 3 apresenta a descrição da ferramenta; Seção 4 possui os Resultados e Discussão; Seção 5 traz a conclusão e trabalhos futuros.

\section{Metodologia}

Inicialmente, realizou-se uma pesquisa bibliográfica [Motta-Roth e Hendges 2010] com trabalhos sobre alfabetização de adultos, visando respaldar a construção da ferramenta. Após, realizou-se uma etnografia virtual [Hine 2005] em tecnologias voltadas para a EJA, como o aplicativo Palma ${ }^{1}$ e o site Luz do Saber ${ }^{2}$, para identificar o processo usado na alfabetização em plataformas digitais, as etapas do aprendizado e as atividades utilizadas em cada etapa.

Na modelagem da aplicação, foi utilizado o Design de Interação [Rogers, Sharp e Preece 2013], que se caracteriza pelos seguintes procedimentos: estabelecer requisitos; criar alternativas de design; prototipar; e avaliar.

Ao estabelecer requisitos propusemos conhecimento mínimo de uso dos recursos de computação (leitura, escrita utilizando mouse, teclado e tela do computador) e navegabilidade (clicar em links, navegar em páginas, sentido de ir e voltar etc.). $\mathrm{Na}$ prototipagem, foram tomados como base os conceitos de Buchenau e Suri (2000), onde os protótipos são representações de um sistema construídos antes que os cenários finais venham a existir de fato. Foram desenhados vários layouts considerando a proposta de

\footnotetext{
${ }^{1} \mathrm{http}: / /$ www.palmaescola.com.br/

${ }^{2}$ https://luzdosaber.seduc.ce.gov.br/eja/
} 
Paulo Freire em seu método de alfabetização, partindo de ações simples para ações mais complexas quanto às práticas de leitura e escrita. Caracteriza-se a proposta freireana de alfabetização de adultos o reconhecimento prévio por parte dos alunos de níveis variados, simples e assistêmicos, de várias formas de letramento.

Após, foram estruturadas as atividades do processo de alfabetização e no esboço inicial do layout do sistema, contendo quatro módulos de conteúdo, que são: 1) apresentação das letras; 2) palavras e sílabas; 3) leitura de textos; 4) produção de textos. Esta metodologia inspira-se no método de alfabetização proposto por Paulo Freire (1979), onde cada módulo possui cinco fases: 1) descoberta do universo vocabular; 2) seleção de palavras dentro do universo vocabular; 3) criação de situações existentes típicas do grupo com o qual se trabalha; 4) elaboração de fichas indicadoras para debates; 5) fichas com famílias fonéticas das palavras-geradoras.

No desenvolvimento da aplicação foram utilizadas as ferramentas GitHub, como repositório em nuvem para armazenamento; Sublime Text Editor, como editor de texto; e a linguagem JavaScript, por ser compatível com todos os browsers disponíveis atualmente; a interface da aplicação foi criada em HTML5 e CSS3.

Após, foi realizado um estudo exploratório [Gil 2008], para tanto, utilizou-se de um questionário qualitativo como técnica de coleta de dados. Como critérios éticos da pesquisa, foi optado pelo sigilo dos nomes dos entrevistados. Para tanto, utilizou-se as letras do alfabeto para identificá-los.

\section{Ferramenta EJA Conectada}

A seguir, são descritas as funcionalidades do sistema e exemplificadas as atividades propostas aos alunos. O design proposto a partir de uma perspectiva de interação homem-máquina apresenta-se em quatro módulos de conteúdos para auxiliar no processo de alfabetização envolvendo duas partes: uma primeira, de conhecimentos do sistema alfabético; uma segunda, de atividades práticas, de exercícios. Ambas as partes estão estruturadas a partir de diversos gêneros textuais em que o sistema alfabético é utilizado tais como jornais, revistas, receitas, notas fiscais, quadrinhos etc.

A página inicial da aplicação, objetiva ser simples, pois os possíveis usuários ainda não têm um bom domínio de leitura, assim, muitas informações e imagens poderiam provocar confusão no uso do sistema. Optou-se por uma imagem de fundo com quadro de sala de aula e mesa com livros com o título do site (Figura 1a). Uma das funcionalidades do sistema é utilizar as práticas de letramento digital básicas como clicar no mouse e utilizar teclados visualizando a tela do computador para a navegação em páginas hipertextuais e hiperlinks.

Ao clicar no botão "Comece Agora" da página inicial, o usuário é direcionado para a página Módulos do Conhecimento (Figura 1b) onde é possível ter acesso as lições e atividades disponibilizadas pelo sistema. Os módulos apresentam uma sequência progressiva de conteúdo, indo do mais básico no módulo 1 (apresentação das letras) a conteúdos mais elaborados no módulo 4 (produção de textos); há também uma sessão com informações referentes ao projeto e aos membros envolvidos (Sobre EJA CONECTADA). 


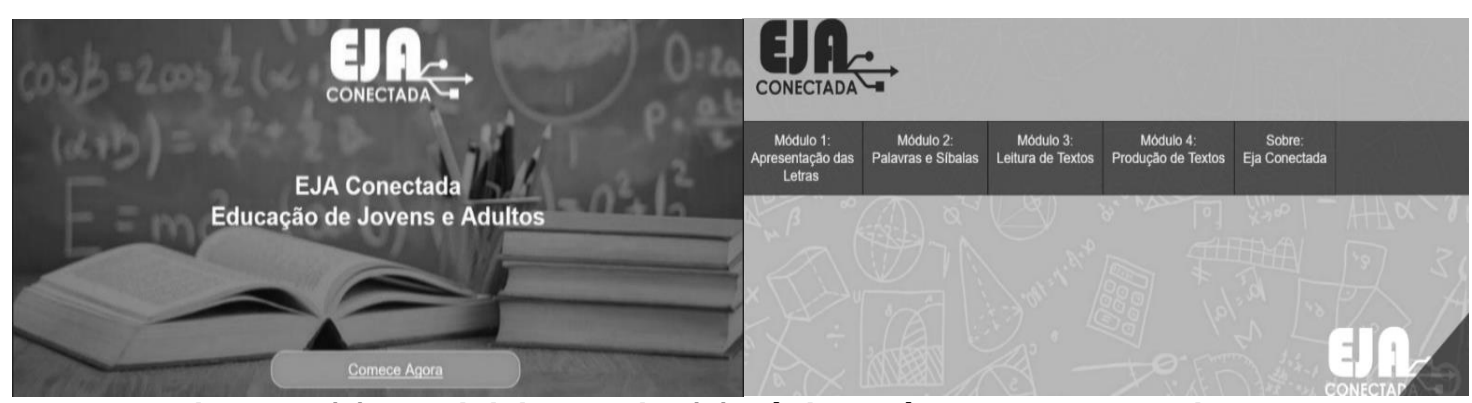

Figura 1. (a) Tela inicial do site (b) Página módulos do conhecimento

Cada módulo segue o mesmo modelo de estrutura, com lições que o usuário pode realizar (Figura 2). Estas lições são separadas em duas etapas, sendo a primeira de "Exploração": nesta fase é apresentado todo o conteúdo do módulo através de exemplos para que o aluno se habitue nas atividades que irá realizar. A segunda parte é a de "Atividades", onde são aplicadas atividades sobre o conteúdo do módulo específico.

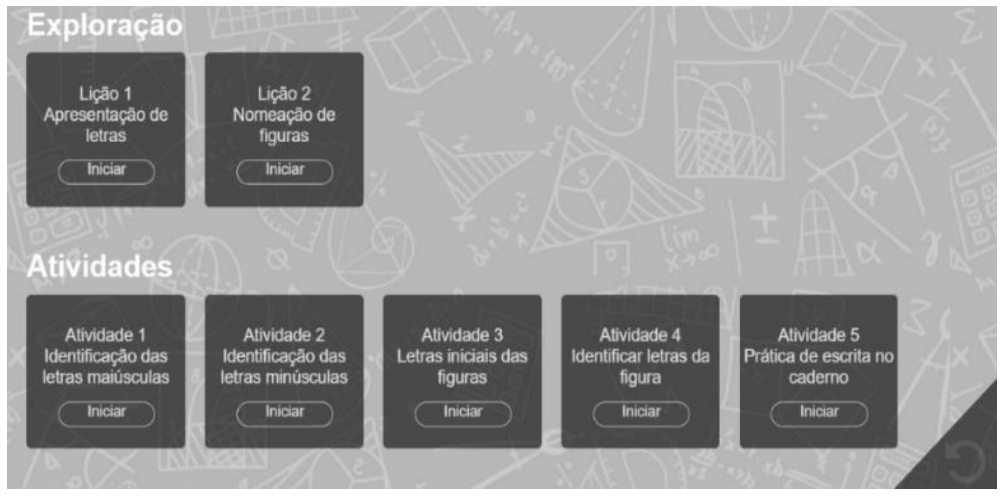

Figura 2. Lições que o usuário pode realizar

O módulo 1 visa familiarizar o aluno com as letras do alfabeto, instigando-o a conhecê-las apresentando o som da letra e sua forma escrita maiúscula e minúscula (Figura 3). Os demais módulos da aplicação seguem o mesmo layout e organização de elementos na tela.

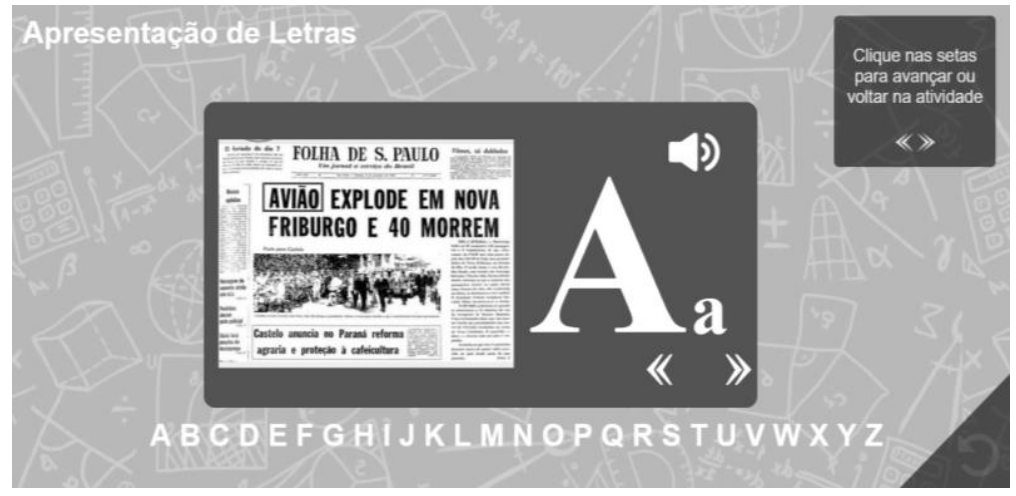

Figura 3. Apresentação das letras (Lição 1)

Na sessão de atividades do módulo 1, o aluno poderá interagir com o sistema e pôr em prática os conhecimentos adquiridos. No início a aplicação emite o som da respectiva letra, como forma de auxílio ao aluno na execução da atividade (Figura4). 


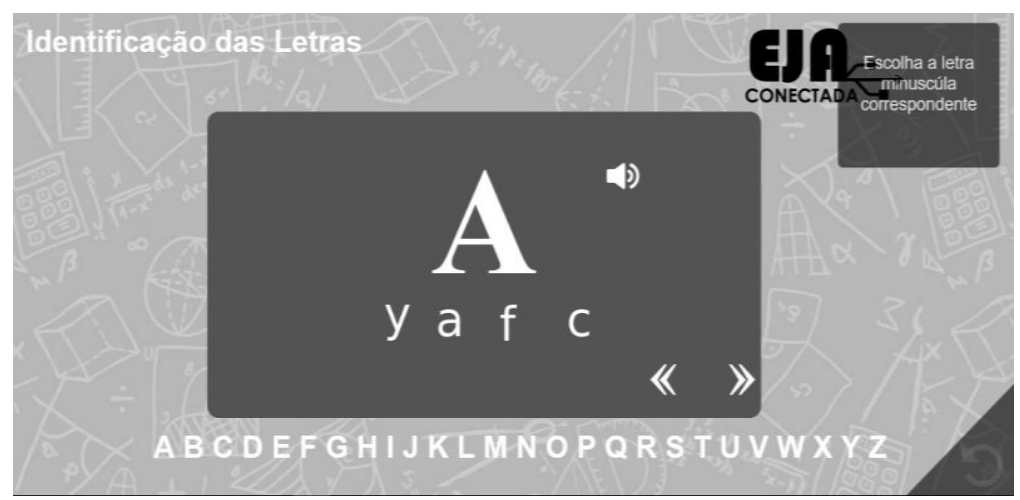

Figura 4. Atividade de identificação das letras minúsculas (Atividade 2)

Para tornar a tela ainda mais interativa, ao clicar nas opções também são emitidos sons sinalizando acerto ou erro. Na Figura 4, é apresentada a letra A, logo abaixo tem-se as opções de letras: $\mathbf{y}, \mathbf{a}, \mathbf{f}, \mathbf{c}$. O aluno acertando, é emitido o som que vai caracterizar o acerto; errando a opção, escutará um som de erro. Logo em seguida, na parte inferior esquerda há as setas duplas de direcionalidade para esquerda (voltar) e para a direita (avançar).

No módulo 2 o aluno aprenderá sobre sílabas, separação silábica e construção de palavras a partir de sílabas, as lições são organizadas da mesma forma que no módulo 1, em "Exploração" e "Atividades". Na sessão "Exploração" do módulo 2, são exibidos vários exemplos de palavras, juntamente com a sua separação silábica, como também exemplos de frases contendo a referida palavra.

Na seção de atividades propostas no módulo 2, o aluno poderá entender como se dá a separação silábica das palavras e de modo interativo poderá pôr em prática o conhecimento adquirido ao longo dos seus estudos. Ao iniciar a Atividade 1, por exemplo, o aluno ouvirá o som da sílaba (CA) e deverá fazer o reconhecimento dela a partir de imagens de objetos que são apresentadas (Figura 5).

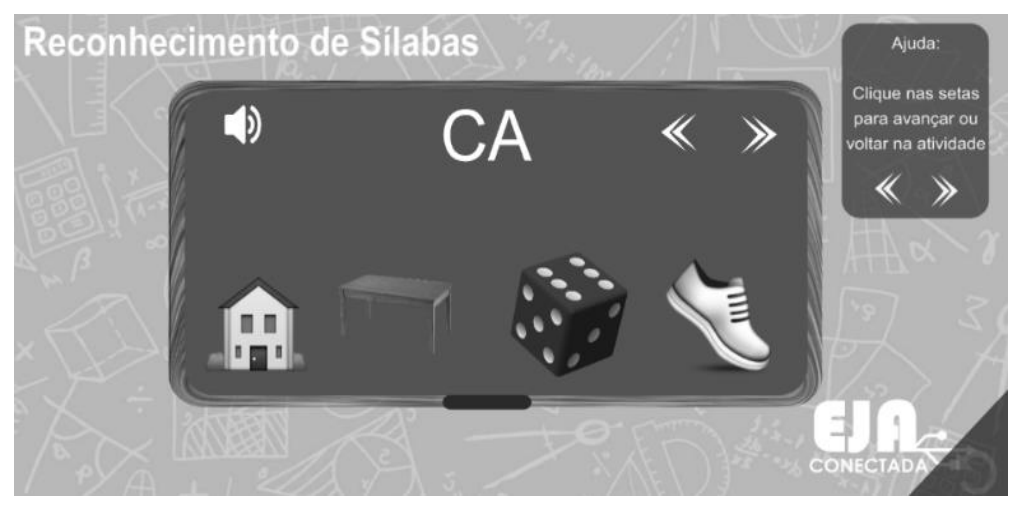

Figura 5. Reconhecimento de sílabas

No exemplo da Figura 5, após o aluno clicar no ícone de som e escutar o som da sílaba ele deverá escolher uma das alternativas de imagens abaixo que correspondem a esta sílaba apresentada (CA): casa, mesa, dado, sapato. A sonoridade de acerto e erro é a mesma utilizada no módulo 1 tornando-se padrão.

No módulo 3 o aluno terá contato com alguns gêneros textuais, que os auxiliarão a conhecer novas palavras e assim, progredir em seu processo de alfabetização. 
Na sessão de atividades do módulo 3, são apresentadas atividades que permitem ao aluno formar palavras com determinadas sílabas apresentadas, e completar as frases, por exemplo; com isso ele pode praticar as habilidades de leitura e se familiarizar com as letras no teclado. Apresentamos a seguir um exemplo de atividades em que é proposto ao aluno escrever uma palavra a partir de sílabas misturadas (Figura 6).

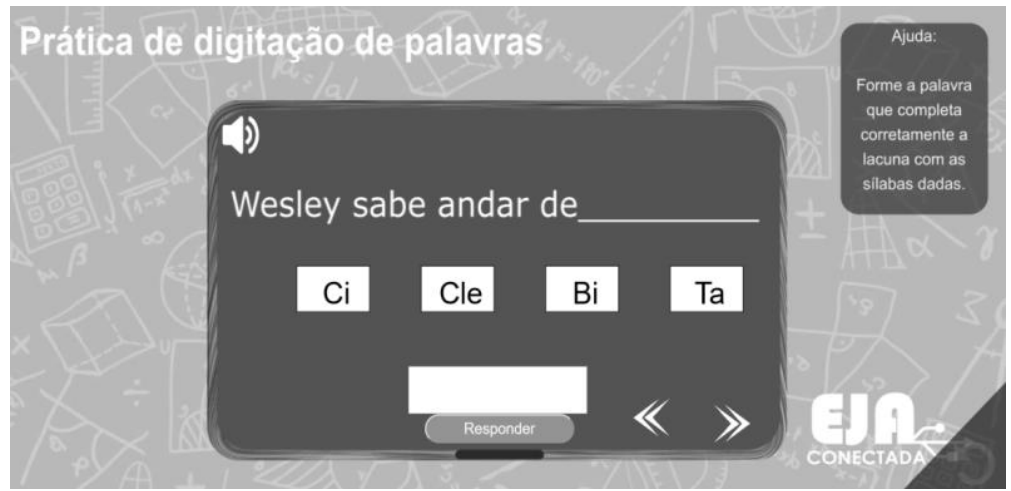

\section{Figura 6. Atividade de digitação de palavras a partir das sílabas (Atividade 3)}

No exemplo da figura 6, temos as sílabas CI-CLE-BI-TA e que devem ser reestruturadas para a construção da palavra BICICLETA completando a frase "Wesley sabe andar de ". Ainda no módulo 3, o aluno estudará as classes gramaticais das palavras, onde dada uma frase, com uma palavra destacada, o aluno deverá apontar a qual classe gramatical pertence aquela frase, se a mesma se trata de um verbo, substantivo, adjetivo, etc.

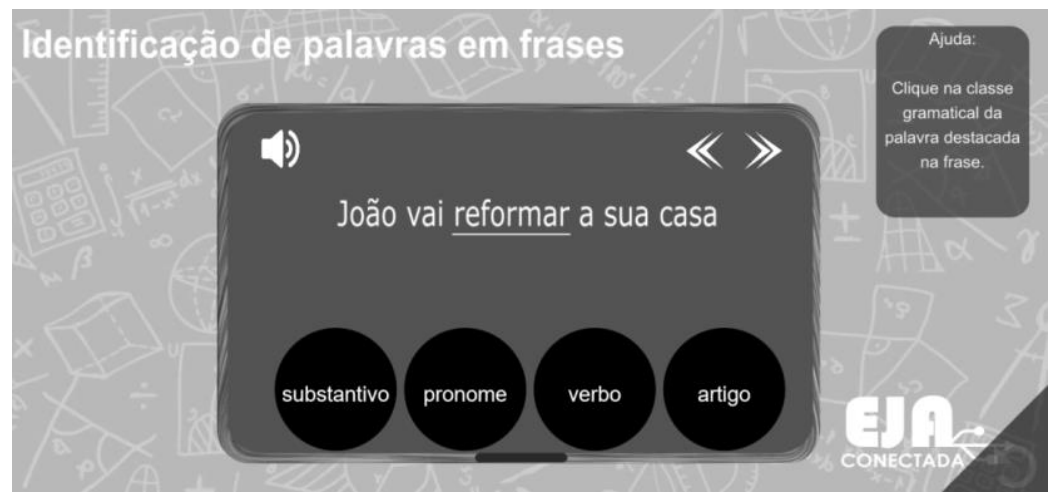

Figura 7. Reconhecimento de palavras em textos (Atividade 4)

No exemplo acima (Figura 7) o aluno deverá reconhecer qual a classe gramatical da palavra REFORMAR, selecionando uma das quatro opções Substantivo, Pronome, Verbo e Artigo. O processo homem-máquina ocorre através da sonorização erro/acerto e através do uso de mouse ou teclado escolhendo as alternativas corretas na tela do computador que projeto a seção de atividade.

O módulo 4 trabalha-se com interpretação de textos, onde são apresentados alguns textos nos mais variados gêneros linguísticos, como cordéis, poesias, letras de músicas, entre outros recursos do gênero, para que seja possível compreender o sentido das palavras e o significado de frases que são empregadas nos textos.

Ao iniciar a lição, o aluno irá para a tela onde são apresentados exemplos de gêneros textuais. Ainda, nestas atividades serão apresentados trechos de músicas ou de poemas (Figura 8) e serão feitas perguntas referentes ao texto apresentado, algumas 
respostas poderão ser encontradas analisando o próprio texto, já outras se fará necessário recorrer a elementos extratextuais e leitura de mundo para que se possa compreender.

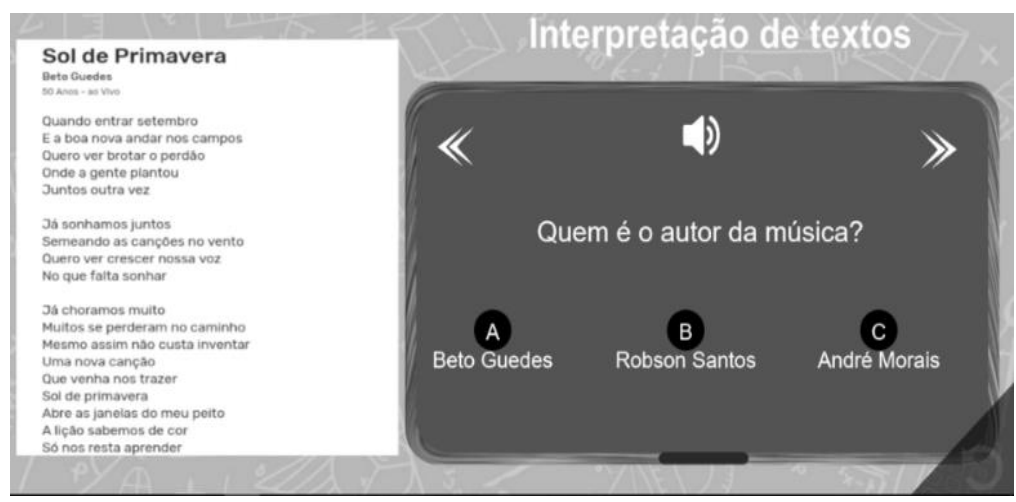

Figura 8. Interpretação de textos (Atividade 3)

No exemplo apresentado acima, na figura 8, tem-se a letra da composição musical Sol de Primavera, cujo título está em negrito com tamanho maior que demais partes do texto, logo abaixo tem-se o nome do compositor da música, no formato negrito e tamanho menor que o título. Ao lado tem-se a pergunta "Qual o autor do texto?" e logo abaixo as opções $\boldsymbol{A}$-Beto Guedes, B-Robson Santos e $\boldsymbol{C}$-André Morais. O aluno deverá responder conforme seja feita a leitura e compreensão do texto.

Ao final do desenvolvimento da ferramenta, foi realizado o registro da aplicação junto ao Instituto Nacional da Propriedade Intelectual - $\mathrm{INPI}^{3}$, com o intuito de assegurar a propriedade intelectual da criação e a proteção ao código fonte.

\section{Resultados e Discussão}

Com o objetivo de obter uma validação inicial da plataforma desenvolvida, foi realizado um experimento em uma escola pública da rede municipal de ensino de uma cidade do Estado do Pernambuco, no mês de outubro de 2019, em uma turma da $2^{\mathrm{a}}$ fase do programa EJA.

Apresentou-se o programa EJA CONECTADA a aluna "A" e foi explicado como mover a seta do mouse no notebook, a aluna não apresenta habilidades com $\mathrm{o}$ computador, porém aprende rápido e se monstra entusiasmada por ter realizado uma ação no aparelho. No Módulo 1: apresentação das letras, lição 1, ela escuta o som da letra "A", mas não identifica que o "A" se encontra no início da palavra destacada, o mesmo acontece nas demais letras do alfabeto que são apresentadas na lição 1 . Na letra "K" ela acerta o nome "Kaká", não por ter lido, mas por reconhecer a imagem do jogador de futebol, outra imagem que ela reconhecesse é a do ex-presidente Michel Temer, e afirma: "ixiii gosto dele não". De alguma forma, ela apesar de não saber ler, está conectada com alguma informação política e faz sua própria leitura de mundo.

Na letra "R", diz que a palavra em destaque é "Cristiano Ronaldo", mas a palavra é Rei. Ela acabou associando a imagem, o que nos mostra mais uma vez que não tem domínio da leitura e provavelmente não tem domínio da escrita. A aluna afirma não ter tido dificuldade com os tamanhos das letras e das imagens nos exemplos apresentados. Ela explica que a parte mais difícil para ela foi utilizar o computador.

\footnotetext{
${ }^{3}$ https://gru.inpi.gov.br/pePI/jsp/programas/ProgramaSearchBasico.jsp Chave de acesso: BR512020000309-5
} 
Na lição 2, ao ser apresentada a palavra "Casa", juntamente com a figura, ela não consegue dizer qual seria a letra inicial, afirma que "essa é a letra mais dificil". Na palavra "dado", ela também diz que é difícil, pois, não sabe a letra que inicia a palavra. Ela dá sequência a lição e depois explica que "achei bom, pra lê um pouquinho que nem eu li, pra se distrair mais". A aluna afirma ainda que com o som da palavra é mais fácil de aprender. Na Atividade 1, onde são apresentadas letras maiúsculas para o aluno clicar nas correspondentes minúsculas, a aluna apresenta muitas dificuldades, não conseguindo identificar as respostas corretas imediatamente, apenas após clicar aleatoriamente nas opções. Esse processo de aprendizagem também é válido, pois o aluno também poderá aprender por meio de suas tentativas e erros. Este teste inicial com a aluna foi realizado em um curto intervalo de tempo, a proposta da aplicação é que a professora realize atividades como essas progressivamente, e na medida em que o conteúdo é ministrado, para que os alunos venham a assimilar o aprendizado.

No módulo 2, são apresentadas palavras e logo abaixo as suas sílabas separadas, juntamente com uma pequena frase de exemplo. Na lição 1, apresenta-se a sílaba "lá" e abaixo a frase "Ela vem de lá", a aluna "A" não consegue identificar a sílaba nem ler a frase, diz que "é mais difícil". Na lição 2, apresentamos alguns exemplos simples de pronomes, verbos e substantivos, no entanto, a aluna diz que nunca estudou essa parte da gramática. Certamente ela os usa em seu cotidiano, mas não relaciona ao assunto que é apresentado. Já na atividade 1: reconhecimento das sílabas, ela tem mais facilidade de acertar "ca" de "casa" e "ja" de "janela", na sílaba "bo" ela confunde com "barco", mas logo em seguida acerta "bola". Por fim, ela identifica as próximas palavras com ajuda do som que é emitido durante o teste, e afirma que essa atividade: "é facinho né, quando aparece o nome aparece a imagem".

$\mathrm{Na}$ atividade 2: reconhecimento das sílabas, em "bra" de braço, ela diz que seria a palavra "brasil", não associando a imagem a sílaba, mas associa ao som da palavra "brasil" quando o "bra" é pronunciado. Nas palavras posteriores, a aluna "A" não consegue relacionar a imagem a sílaba sem o auxílio do som das palavras e sílabas que é pronunciado no momento do teste.

$\mathrm{Na}$ atividade 3, onde é necessário separar a palavra em sílabas, a aluna apresenta dificuldades em localizar algumas letras no teclado para digitar as sílabas, ao encontrar uma das letras desejadas ela a aperta várias letras, isso decorre da falta de familiaridade com o equipamento.

$\mathrm{Na}$ atividade 4: forme palavras com sílabas, ela coloca as sílabas na mesma ordem que aparecem, ou seja, embaralhadas. A aluna " $A$ " encontrou muitas barreiras ao testar o programa, tanto na parte de alfabetização quanto na parte de manuseio do computador, mas embora isso tenha ocorrido, ela diz que: "eu acho bom (sobre o programa), porque o caba já aprende mais, digitando as letras normal organizada".

$\mathrm{O}$ aluno "B" no módulo 1 , na atividade 1 onde pede para identificar as letras maiúsculas, responde corretamente toda atividade, sem apresentar dificuldades e diz ser muito fácil, porém, como vimos anteriormente, existem alunos que necessitam de atividades mais simples, desde o começo da alfabetização com o reconhecimento das letras. Por isso, no EJA CONECTADA existem vários níveis de dificuldades. $\mathrm{Na}$ atividade 2 , identificação de letras minúsculas, ele também realiza corretamente, sem apresentar problemas com o computador ou com o alfabeto. $\mathrm{Na}$ atividade 3: letras 
iniciais das figuras, o aluno responde corretamente, e o mesmo se repete nas atividades seguintes, em todas ele afirma estar muito fácil e diz que deveria ser mais complexo.

No módulo 2: palavras e sílabas, na atividade 1: reconhecimento de sílabas, ele consegue ler as sílabas, e erra algumas palavras, aparentemente as sílabas para o aluno "B" se torna mais complicado por se tratar de mais de uma letra, porém ele afirma que achou fácil. Ao final, ele afirma que a aplicação ajuda: "Por que é separando sílaba que aprende mais né, é legal (...). Gostei do programa queria aprender mais, porque é conhecimento mais do computador, faz tempo que eu não mexo no computador, tá com dez anos que eu não mexi, faz tempo já, quero mais aprender ter conhecimento e aprender mais um pouco".

$\mathrm{O}$ aluno "C", na lição 1 do módulo 1 , desde a primeira letra "A", ele consegue associar a letra a palavra destacada na imagem de jornal. Nas atividades 1, 2, 3 e 4 ele identifica corretamente as letras, e consegue resolver as questões sem muitas dificuldades, o que demonstra que tem domínio sobre o reconhecimento do alfabeto. No módulo 2: palavras e sílabas, na atividade 3, onde era necessário digitar corretamente a separação silábica das palavras, o aluno apresenta certa dificuldade, por falta do hábito de digitação, que o impede de localizar as letras no teclado com agilidade.

Com os relatos, observa-se que os alunos apresentam níveis diferentes de aprendizagem, mesmo estando na primeira ou segunda fase, algumas atividades são simples para quem já possui domínio mínimo sobre o alfabeto. Outras atividades, são mais complexas a depender dos conhecimentos apreendidos e evolução dos alunos. Ao final do processo de validação, foi observado que existe uma diversidade de alunos e de ideias no ensino EJA. Aprender demanda novos modos de construção, se constituindo numa exigência social, sendo inevitável para o desenvolvimento pessoal, profissional e econômico das pessoas.

\section{Conclusão}

Este trabalho teve como objetivo apresentar a construção de uma ferramenta tecnológica, voltada para a Educação de Jovens e Adultos, que disponibiliza diversas atividades educativas através de recursos de imagem, sons e conteúdo. Por se tratar de uma ferramenta online, todo o conteúdo pode ser facilmente acessado através de qualquer computador conectado à internet. A proposta é ser utilizada com a mediação do professor em sala inclusive possibilitando outras práticas não previstas no sistema e que podem ser exploradas pelo professor em sala de aula, tanto complementando como fazendo parte do conteúdo didático.

Foi possível observar que não há muitos recursos tecnológicos voltados a alfabetização de adultos. Por se tratar de um público que já possui muitos conhecimentos e experiências de vida, faz-se necessário a utilização de ferramentas adequadas, que não infantilizem o adulto em seu processo de alfabetização. Por isso mesmo selecionamos os diversos gêneros textuais que fazem parte da vida e do mundo de conhecimento dos jovens e adultos.

Como trabalhos futuros, é possível verificar de forma mais consistente e em maior escala, a aplicação da ferramenta em ambientes de ensino, buscando a avaliação dos alunos e profissionais da área e a expansão do uso da ferramenta para escolas e municípios que ofertam turmas de EJA. Assim, conforme avaliação do público-alvo, 
IX Congresso Brasileiro de Informática na Educação (CBIE 2020)

Anais do XXVI Workshop de Informática na Escola (WIE 2020)

pretende-se também incluir novas atividades na ferramenta, buscando aumentar o engajamento dos alunos.

\section{Referências}

Braga, A. C. and Mazzeu, F. J. C. (2017). O analfabetismo no Brasil: lições da história. Revista on line de Política e Gestão Educacional, 24-46.

Buchenau, M. and Suri, J. F. (2000). Experience prototyping. In Proceedings of the 3rd conference on Designing interactive systems: processes, practices, methods, and techniques (pp. 424-433).

Freire, P. (1979). Conscientização Teoria e Prática da Libertação Uma Introdução ao Pensamento de Paulo Freire, Cortex \& Moraes, São Paulo.

Gil, A. C. (2008). Métodos e técnicas de pesquisa social. 6. ed. Editora Atlas SA.

Hine, C. (2005). Virtual methods: Issues in social research on the Internet. Berg Publishers.

IBGE. Instituto Brasileiro de Geografia e Estatística. (2018). "Pesquisa nacional por amostra de domicílios contínua-PNAD contínua. Divulgação anual, https://biblioteca.ibge.gov.br/visualizacao/livros/liv101657_informativo.pdf, Dezembro.

Jenkings, H. (2009). Cultura da convergência: a colisão entre os velhos e novos meios de comunicação. São Paulo: Aleph.

Leal, T. F., Albuquerque, E. B. C. D. and Morais, A. G. D. (2010). Alfabetizar letrando na EJA: fundamentos teóricos e propostas didáticas. Belo Horizonte: Autêntica.

Lévy, P. (1999). Cibercultura. São Paulo: Editora 34.

Motta-Roth, D. and Hendges, G. R. (2010). Produção textual na universidade. São Paulo: Parábola Editorial, 15, 16.

Oliveira, K. K. de S., Andrade, C. W. L., Segundo, J., Cândido, A. L., Oliveira, A., Machado, A. S., Britto, A. C. Vilar, G. (2019). Tecnologias na Educação Básica uma Pesquisa Ação com Professores de uma Escola Pública Municipal. In Anais do Workshop de Informática na Escola (Vol. 25, No. 1, p. 1054).

Ortiz, J. S. B, Silva Junior, D., Oliveira, C. M. and Pereira, R. (2019). Pensamento Computacional e Cultura Digital: discussões sobre uma prática para o letramento digital. In Brazilian Symposium on Computers in Education (Simpósio Brasileiro de Informática na Educação-SBIE) (Vol. 30, No. 1, p. 1241).

Rogers, Y., Sharp, H. and Preece, J. (2013). Design de Interação: Além da Interação Humano-Computador. Porto Alegre, Brasil: Bookman.

Santaella, L. (2008). A ecologia pluralista da comunicação: conectividade, mobilidade e ubiquidade. São Paulo: Paulus.

Silva, T. M., Soares, L., Oliveira, K. K. S, Barbosa, R., Santos, H. and Alves, G. (2019). Experiência com gamificação: Uma abordagem aplicada no ambiente virtual de aprendizagem Moodle. In Anais do Workshop de Informática na Escola (Vol. 25, No. 1, p. 677).

Val, M. D. G. C. (2006). O que é ser alfabetizado e letrado. Práticas de leitura e escrita. Brasilia: Ministério da Educação, 18-23. 